\title{
Reducing Systematic Review to a Cut and Paste
}

\author{
Andrew J. Vickers \\ Memorial Sloan-Kettering Cancer Center, New York, NY, USA
}

I first became involved in systematic review when it was still relatively controversial. I remember it being argued that reviews inevitably led one to 'combine apples and oranges'; I also remember talk about 'the end of systematic review' after a randomized trial of magnesium for myocardial infarct failed to confirm promising results from a meta-analysis. Neither of these arguments has stood the test of time. But I also remember it being said that systematic review allowed investigators to pump out meaningless re-analyses of published trials in place of the more demanding, and scientifically productive, work of collecting new data. At the time I thought that this was a rather silly point. It turns out that I was wrong.

Over the years, I have tried to keep abreast of the latest systematic reviews on acupuncture, particularly with respect to my work for the Acupuncture Trialists' Collaboration [1, 2]. One cannot help but notice that many acupuncture reviews concern rather narrow indications that are not an important component of contemporary clinical practice. For example, until I saw the systematic review, I had never heard of acupuncture being a treatment for schizophrenia [3]. Similarly, I was first made aware that moxibustion could be used to treat chemotherapy nausea by reading the review [4], perhaps odd given that I work in a cancer hospital and have conducted research on acupuncture for cancer-related symptoms.

What also leaps out from even the most cursory reading of the review abstracts is that the conclusions are almost identi- cal. Text box 1 gives the conclusions from the abstracts of several acupuncture systematic reviews. In almost every case, the evidence is described as 'insufficient', 'limited' or 'not convincing'. The authors then typically call for 'further research' or 'rigorously designed trials'. Careful reading of the papers themselves redoubles the sense of déjà vu: text box 2 cites text from the research methods of some reviews. There is a remarkable consistency, as if systematic review was little more than putting batter in a cake mold and then letting the oven do its work.

In my personal opinion, these reviews are empty scientific exercises that teach us nothing. For example, did anyone really believe that there were convincing data in favor of acupuncture relieving hot flashes in men with prostate cancer? If not, what have we learned when a reviewer tells us that 'the evidence is not convincing'? Moreover, what about those calls for 'further research': are these careful analyses of research priorities or simply more cut and paste? Were the reviewers seriously considering conducting a randomized trial on, say, moxibustion for hypertension? If not, in what way do they believe that their review has helped other researchers?

The systematic reviews cited here confirm the predictions of those early critics of systematic review: they make the reviewer appear scientifically productive, but they do little to further science, or help relieve human suffering.

\section{References}

1 Vickers AJ, Maschino AC: The acupuncture trialists' collaboration: Individual patient data metaanalysis of chronic pain trials. Acupunct Med 2009; 27:126-127.

2 Vickers AJ, Cronin AM, Maschino AC, Lewith G, Macpherson H, Victor N, Sherman KJ, Witt C, Linde K: Individual patient data meta-analysis of acupuncture for chronic pain: Protocol of the acupuncture trialists' collaboration. Trials 2010;11:90.

3 Lee MS, Shin BC, Ronan P, Ernst E: Acupuncture for schizophrenia: A systematic review and metaanalysis. Int J Clin Pract 2009;63:1622-1633.
4 Lee MS, Choi TY, Park JE, Lee SS, Ernst E: Moxibustion for cancer care: A systematic review and meta-analysis. BMC Cancer 2010;10:130.

$\checkmark 5$ Kim JI, Choi JY, Lee H, Lee MS, Ernst E: Moxibustion for hypertension: A systematic review. BMC Cardiovasc Disord 2010;10:33.

6 Cho SH, Lee H, Ernst E: Acupuncture for pain relief in labour: A systematic review and metaanalysis. BJOG 2010;117:907-920.

7 Lee DH, Kim JI, Lee MS, Choi TY, Choi SM, Ernst E: Moxibustion for ulcerative colitis: A systematic review and meta-analysis. BMC Gastroenterol 2010;10:36.
8 Lee MS, Shin BC, Choi TY, Ernst E: Acupuncture for treating dry eye: A systematic review. Acta Ophthalmol 2010, Epub ahead of print.

9 Lee MS, Shin BC, Kim JI, Han CH, Ernst E: Moxibustion for stroke rehabilitation: Systematic review. Stroke 2010;41:817-820.

10 Lee MS, Shin BC, Ernst E: Acupuncture for Alzheimer's disease: A systematic review. Int J Clin Pract 2009;63:874-879.

11 Lee MS, Pittler MH, Shin BC, Kim JI, Ernst E: Acupuncture for allergic rhinitis: A systematic review. Ann Allergy Asthma Immunol 2009;102:269-279; quiz 279-281, 307.

\section{KARGER}

Fax +497614520714

Information@Karger.de

www.karger.com

\section{(C) 2010 S. Karger GmbH, Freiburg}

Accessible online at:

www.karger.com/fok
Andrew J. Vickers, PhD

Department of Epidemiology and Biostatistics

Memorial Sloan-Kettering Cancer Center

1275 York Avenue New York, NY 10065, USA

Tel. +1 646 735-8142, Fax -0011

vickersa@mskcc.org 
12 Lee MS, Shin BC, Ernst E: Acupuncture for treating erectile dysfunction: a systematic review. BJU Int 2009;104:366-370.

13 Lee MS, Kim KH, Shin BC, Choi SM, Ernst E: Acupuncture for treating hot flushes in men with prostate cancer: A systematic review. Support Care Cancer 2009:17:763-770.

14 Lee MS, Shin BC, Ernst E: Acupuncture for treating menopausal hot flushes: A systematic review. Climacteric 2009;12:16-25.
15 Lee MS, Kim KH, Choi SM, Ernst E: Acupuncture for treating hot flashes in breast cancer patients: A systematic review. Breast Cancer Res Treat 2009; 115:497-503.

16 Lee MS, Shin BC, Suen LK, Park TY, Ernst E: Auricular acupuncture for insomnia: A systematic review. Int J Clin Pract 2008;62:1744-1752.
7 Lee MS, Shin BC, Ernst E: Acupuncture for rheumatoid arthritis: A systematic review. Rheumatology (Oxford) 2008;47:1747-1753.

18 Lee MS, Shin BC, Kong JC, Ernst E: Effectiveness of acupuncture for Parkinson's disease: A systematic review. Mov Disord 2008;23:1505-1515.

19 Mayhew E, Ernst E: Acupuncture for fibromyalgia - a systematic review of randomized clinical trials. Rheumatology (Oxford) 2007;46:801-804

1 These results provide limited evidence for the effectiveness of acupuncture in treating the symptoms of schizophrenia. However, the total number of RCTs, the total sample size and the methodological quality were too low to draw firm conclusions. As all studies originated from China, international studies are needed to test whether there is any effect [3].

2 CONCLUSION: The evidence is limited to suggest moxibustion is an effective supportive cancer care in nausea and vomiting. However, all studies have a high risk of bias so effectively there is not enough evidence to draw any conclusion. Further research is required to investigate whether there are specific benefits of moxibustion for supportive cancer care [4].

3 CONCLUSION: There is insufficient evidence to suggest that moxibustion is an effective treatment for hypertension. Rigorously designed trials are warranted to answer the many remaining questions [5].

4 CONCLUSIONS: The evidence from RCTs does not support the use of acupuncture for controlling labour pain. The primary studies are diverse and often flawed. Further research seems warranted [6].

5 Current evidence is insufficient to show that moxibustion is an effective treatment of [ulcerative colitis]. Most of included trials had high risk of bias. More rigorous studies seem warranted [7].

6 Conclusion: These results provide limited evidence for the effectiveness of acupuncture for treating dry eye. However, the total number of RCTs, the total sample size and the methodological quality were too low to draw firm conclusions [8].

7 CONCLUSION: This systematic review found limited effectiveness of moxibustion as an adjunct to standard care in stroke rehabilitation [9].

8 Even though the number of studies is small, the existing evidence does not demonstrate the effectiveness of acupuncture for [Alzheimer's disease] [10].

9 CONCLUSIONS: The evidence for the effectiveness of acupuncture for the symptomatic treatment or prevention of AR [allergic rhinitis] is mixed. The results for seasonal AR failed to show specific effects of acupuncture. For perennial AR, results provide suggestive evidence of the effectiveness of acupuncture [11].

10 CONCLUSION: The evidence is insufficient to suggest that acupuncture is an effective intervention for treating [erectile dysfunction]. Further research is required to investigate whether there are specific benefits of acupuncture for men with ED [12].

11 CONCLUSION: The evidence is not convincing to suggest acupuncture is an effective treatment for hot flush in patients with [prostate cancer]. Further research is required to investigate whether acupuncture has hot-flush-specific effects [13].

12 CONCLUSION: Sham-controlled RCTs fail to show specific effects of acupuncture for control of menopausal hot flushes. More rigorous research seems warranted [14].

13 In conclusion, the evidence is not convincing to suggest acupuncture is an effective treatment of hot flash in patients with breast cancer. Further research is required to investigate whether there are specific effects of acupuncture for treating hot flash in patients with breast cancer [15].

14 CONCLUSION: We conclude that, because of the paucity and of the poor quality of the data, the evidence for the effectiveness of [auricular acupuncture] for the symptomatic treatment of insomnia is limited. Further, rigorously designed trials are warranted to confirm these results [16].

15 In conclusion, penetrating or non-penetrating sham-controlled RCTs failed to show specific effects of acupuncture for pain control in patients with [rheumatoid arthritis]. More rigorous research seems to be warranted [17].

16 In conclusion, the evidence for the effectiveness of acupuncture for treating [Parkinson's disease] is not convincing. The number and quality of trials as well as their total sample size are too low to draw any firm conclusion. Further rigorous trials are warranted [18].

17 CONCLUSION: The notion that acupuncture is an effective symptomatic treatment for fibromyalgia is not supported by the results from rigorous clinical trials. On the basis of this evidence, acupuncture cannot be recommended for fibromyalgia [19]. 


\section{Acupuncture for schizophrenia [3]}

'All articles were read by two independent reviewers.'

'... data from the articles were validated and extracted according to predefined criteria.'

'Risk of bias was assessed using the Cochrane classification in four criteria.'

'Considering that it is very hard to blind therapists to the use of acupuncture ...'

'Discrepancies were resolved through discussions between two reviewers ... and if needed, by seeking the opinion of a third reviewer.'

'There were no disagreements between the three reviews about the assessment of risk of bias.'

\section{Moxibustion for cancer [4]}

'All articles were read by three independent reviewers ...'

'Data from the articles were validated and extracted according to pre-defined criteria.'

'Risk of bias was assessed using the Cochrane classification in four criteria.'

'Considering that it is hard to blind therapists to the use of moxibustion ...'

'Disagreements were resolved by discussion between the two reviewers.'

'There were no disagreements between the three reviews about the risk of bias.'

\section{Moxibustion for ulcerative colitis [7]}

'All articles were read by two independent reviewers ...'

'... data from the articles [were extracted] according to predefined criteria.'

'Risk of bias was assessed using the Cochrane classification in four criteria.'

'Considering that it is virtually impossible to blind therapists to the use of moxibustion ...'

'Disagreements were resolved by discussion between the two reviewers ... with the opinion of a third reviewer ... being sought if necessary.'

'There was no disagreement between the two reviewers about the risk of bias.'

Acupuncture for Alzheimer's disease [10]

'All articles were read by two independent reviewers ...'

'... data from the articles were validated and extracted according to predefined criteria.'

'We used a modification of the Jadad scale. ...'

'Discrepancies were resolved through discussions between the two reviewers ... and if needed, by seeking the opinion of a third reviewer.'

\section{Hot flashes prostate cancer [13]}

'All articles were read by two independent reviewers ...'

'Data from the articles [were extracted] according to predefined criteria.'

'The modified Jadad score was calculated ...'

'It is impossible to blind therapists to the use of acupuncture ...'

'Disagreements were resolved by discussion between the two reviewers ..., with the opinion of a third reviewer ... obtained if necessary.'

\section{Acupuncture for rheumatoid arthritis [17]}

'All articles were read by two independent reviewers ...'

'... data from the articles were validated and extracted according to the pre-defined criteria.'

'... a modified version of the Jadad score [was calculated].'

'Since it is virtually impossible for an acupuncturist to be blinded to the treatment ...'

'Discrepancies were resolved through discussions between two reviewers ... and if needed, by seeking the opinion of the senior author ...'

Text box 2. Methods sections from acupuncture systematic reviews. 